\title{
Early recovery of the platelet count after decitabine-based induction chemotherapy is a prognostic marker of superior response in elderly patients with newly diagnosed acute myeloid leukaemia
}

\author{
Jiayu Huang ${ }^{1}$, Huihui Zhao ${ }^{1,2}$, Ming Hong ${ }^{1}$, Han Zhu' ${ }^{1}$ Yu Zhu', Yun Lian' ${ }^{1}$ Shan Li', Jianyong Li ${ }^{1}$ and Sixuan Qian ${ }^{1 *}$ (D)
}

\begin{abstract}
Background: Definite prognostic clinical factors of benefit for decitabine-based induction chemotherapy in elderly patients newly diagnosed with acute myeloid leukaemia (AML) are not identified. This study was designed to explore the potential biomarker, especially regeneration of haematopoiesis, of treatment response and survival in elderly patients with newly diagnosed AML.

Method: We analysed the clinical data of 117 elderly AML patients who were treated with a decitabine dose of 15 $\mathrm{mg} / \mathrm{m}^{2}$ for 5 days, granulocyte colony-stimulating factor of $300 \mathrm{\mu g} / \mathrm{d}$ for priming, plus cytarabine $10 \mathrm{mg} / \mathrm{m}^{2} \mathrm{q} 12 \mathrm{~h}$ for 7 days and aclarubicin $10 \mathrm{mg} / \mathrm{d}$ for 4 days (D-CAG).

Results: After initial induction chemotherapy, the overall response rate and complete remission (CR) were 71.8\% and $58.1 \%$, respectively. Patients responding to the D-CAG regimen achieved higher platelet counts on day 14 after initial treatment $(p<0.001)$. Median counts were $59.5 \times 10^{9} / \mathrm{L}$ in the $\mathrm{CR}$ group, $37 \times 10^{9} / \mathrm{L}$ in the partial remission group and $28 \times 10^{9} / \mathrm{L}$ in the non-responsive group. We then classified patients into those who achieved platelet counts $\geq 60 \times$ $10^{9} / \mathrm{L}$ or $100 \times 10^{9} / \mathrm{L}$ on day 14 after D-CAG vs. those who did not. Platelet counts $\geq 60 \times 10^{9} / \mathrm{L}$ or $100 \times 10^{9} / \mathrm{L}$ on day 14 were significantly associated with superior $C R$, overall survival and disease-free survival $(80.9 \%$ vs. $45.3 \% p<0.001,16.5$ vs. 9.1 months $p=0.009$ and 16.3 vs. 7.4 months $p=0.024 ; 85.2 \%$ vs. $50 \% p=0.001,31$ vs. 10.1 months $p=0.003$ and 16.9 vs. 8.9 months $p=0.006)$. Multivariate analysis confirmed that poor cytogenetics $(p=0.010)$ and FLT3-ITD mutation $(p=0$. 007) were identified as independent factors of OS, but not platelet count $(p=0.091)$. However, platelet count $\geq 100 \times 10^{9} /$ $L$ on day 14 was an independent prognostic factor of CR and DFS.
\end{abstract}

Conclusion: Platelet count recovery on day 14 after D-CAG induction chemotherapy is associated with response.

Trial registration: D-CAG regimen was registered on ChicTR with number 11001700.

Keywords: Platelet recovery, Prognostic indicator, Decitabine, Acute myeloid leukaemia, Elderly

\footnotetext{
* Correspondence: qiansx@medmail.com.cn

${ }^{1}$ Department of Hematology, The First Affiliated Hospital of Nanjing Medical

University, Jiangsu Province Hospital, 300 Guangzhou Road, Nanjing 210029,

China

Full list of author information is available at the end of the article
}

(c) The Author(s). 2018 Open Access This article is distributed under the terms of the Creative Commons Attribution 4.0 International License (http://creativecommons.org/licenses/by/4.0/), which permits unrestricted use, distribution, and reproduction in any medium, provided you give appropriate credit to the original author(s) and the source, provide a link to the Creative Commons license, and indicate if changes were made. The Creative Commons Public Domain Dedication waiver (http://creativecommons.org/publicdomain/zero/1.0/) applies to the data made available in this article, unless otherwise stated. 


\section{Background}

Acute myeloid leukaemia (AML) develops from clonal malignant disorders of haematopoietic stem cells, with a median age at diagnosis of 68 years [1]. Because of clinically and biologically heterogeneous features, elderly AML patients have poor prognosis attributable to increased resistance to current standard cytotoxic agents and/or poor tolerance of intensive induction chemotherapy; the rate of treatment-related mortality rate is $25-40 \%[1,2]$. Currently, decitabine is the appealing approach for AML patients who are not applicable for intensive induction chemotherapy. In a phase III study enrolling elderly patients ( $\geq 60$ years) with previously untreated AML, decitabine resulted in a response rate (complete remission $(\mathrm{CR})$ plus the $\mathrm{CR}$ without platelet recovery) of $17.8 \%$ and a median overall survival (OS) of 7.7 months [3]. However, this regimen was associated with low survival rates. The combination of decitabine and cytotoxic agents has been well established to trigger superior outcome and good tolerance for older or relapsed patients with AML $[4,5]$. Our previous published study showed the regimen of low-dose decitabine, aclarubicin, cytarabine in combination with granulocyte stimulating factor (D-CAG) led to better results for elderly AML patients, with CR of $64.7 \%$ and median survival of 10 months [4]. Epigenetic changes are implicated in the mechanism of AML development and the hypomethylating agents received the US Food and Drug Administration approval for treatment in elderly AML patients. Methylation studies have shown global- and gene-specific hypermethylation in MDS and AML, but there seems to be little relation between the degree of demethylation following hypomethylating treatment and haematological response [6-8]. Effective methods for identifying AML patients who are most likely to respond to treatment with decitabine would be of immediate clinical utility [9].

In clinical practice, specific chromosome abnormalities and molecular genetic changes are of particular interest in term of prognosis, thus may be used for stratifying patients with AML at different risks, which contributes for identifying appropriate therapeutic strategies [10]. However, their ability to predict response or survival on decitabine therapy is not be distinctly elucidated [11]. Recently, low-dose decitabine has been shown to promote megakaryocyte maturation and platelet production [12, 13]. Platelet response was identified as an independent positive predictor of overall response and OS [14-16]. To our knowledge, the prognostic importance of platelet counts before haematological recovery for response to decitabine alone or decitabine-based chemotherapy, such as D-CAG, remains unknown. Therefore, it is hoped that early recovery in the platelet count before haematological recovery will allow us to optimize treatment of distinct subtypes of AML receiving decitabine-based chemotherapy.
In the analysis of this study, we analysed baseline biomarkers, molecular mutation, clinical variables, and regeneration of haematopoiesis after a first cycle of D-CAG chemotherapy to investigate a prognostic marker of $\mathrm{CR}$ and OS in elderly AML patients.

\section{Patients and methods \\ Patients}

One hundred and seventeen patients aged $\geq 60$ years with newly diagnosed de novo or secondary AML (Additional file 1) according to the International Working Group criteria was enrolled in this study [17]. We compiled the routine blood values of the patients receiving D-CAG on day 7, 10 and 14 after chemotherapy. The study procedures and informed consent forms were approved by the ethic committee of the First Affiliated Hospital of Nanjing Medical University, Jiangsu Province Hospital with number 2011-SR-085 and also registered on ChicTR with number 11001700. All patients or their legal trustee provided written informed consent.

\section{Treatment}

All patients were administered decitabine at a dose of 15 $\mathrm{mg} / \mathrm{m}^{2}$ intravenously (day $1-5$ ) and granulocyte colonystimulating factor of $300 \mu \mathrm{g} / \mathrm{d}$ (day 0-9) for priming in combination with cytarabine $10 \mathrm{mg} / \mathrm{m}^{2} \mathrm{q} 12 \mathrm{~h}$ (day 3-9) and aclarubicin $10 \mathrm{mg} / \mathrm{d}$ (day 3-6) (D-CAG) as induction therapy. Hydroxyurea was permitted as rescue medication to control white blood cells (WBC) to $<5.0 \times 10^{9} / \mathrm{L}$ but was discontinued at least $24 \mathrm{~h}$ before decitabine treatment. Red cells and platelets were infused if haemoglobin $(\mathrm{Hb})$ was under $70 \mathrm{~g} / \mathrm{L}$ or platelet count under $20 \times 10^{9} / \mathrm{L}$. Patients who did not achieve CR or partial remission (PR) were offered alternative therapies. Post-remission therapy consisted of 4-6 cycles D-CAG or conventional chemotherapy [4].

\section{Study assessments}

Bone marrow aspiration was performed when peripheral hemogram recovered, or 3-4 weeks after chemotherapy. Cytogenetic risk groups and treatment response were determined by European Leukaemia Net [18] and International Working Group criteria [17]. Mutation analysis of four relevant molecular marker genes was carried out as described previously [4].

To quantify objective responses, CR was defined as normalization of bone marrow blasts $(\leq 5 \%$ blasts $)$ and peripheral blood neutrophil count $\geq 1.0 \times 10^{9} / \mathrm{L}$, platelet count $>100 \times 10^{9} / \mathrm{L}$. PR was defined as morphologic CR and $5-15 \%$ blasts with a decrease of at least $50 \%$ of total bone marrow blasts. The overall response rate (ORR) incorporated rates of CR and PR. All other patients were considered non-responders.

OS was measured from day 14 after the first cycle chemotherapy to the date of death from any causes or 
last follow-up. Disease-free survival (DFS) was calculated from the date of achievement of CR to an event, including relapse, death or last follow-up.

\section{Statistical analysis}

Differences to response treatment efficacy in subgroups according to platelet count were evaluated using the rank sum test for non-normal data. Patient characteristics were compared using $\mathrm{T}$ test (counting variables), Chi-square test or Fisher's exact test (categorical variables) between patients who did or did not achieve platelet count $\geq 60 \times 10^{9} / \mathrm{L}$ or $100 \times 10^{9} / \mathrm{L}$. The Chi-square test was also adopted for analysis of remission rate difference. A step multivariable logistic regression model was conducted for CR and ORR, as well as included covariates significant on univariate analysis. Kaplan-Meier method was performed to estimate the median survival and log-rank test was used to compare survival curves. To assess the independent prognostic variable on OS, hazard ratios (HR) and 95\% confidence interval (CI) were calculated by using a Cox proportional hazards model. The covariates included ECOG PS, cytogenetic risk, FLT3-ITD and platelet count $\geq 100 \times 10^{9} / \mathrm{L}$. A $P$ value $<0.05$ was considered statistically significant. All statistical analyses were performed by using SPSS Version 20 software.

\section{Results}

\section{Patient characteristics}

From September 2011 to April 2016, 117 newly diagnosed elderly AML patients were included in the study. The median age at diagnosis was 67 years (range: 60 to 87 years) with a male/female ratio of 1.21:1. Patients diagnosed with acute promyelocytic leukaemia were excluded from this study. Among those cases, 36 (30.8\%) patients were aged 70 to 79 , and $9(7.7 \%)$ patients were aged 80 years or older. Baseline clinical characteristics for all patients are shown in Table 1.

Pre-treatment cytogenetics were determined in 108 (92.3\%) patients: 1 (0.8\%) had good cytogenetics, 18 (15.4\%) had poor cytogenetics, and the remaining 89 (76.1\%) had intermediate cytogenetics.

At the time of diagnosis of AML, the patients' median WBC count was $6.92(0.3-310.3) \times 10^{9} / \mathrm{L}$, the median $\mathrm{Hb}$ level was $84(47-139) \mathrm{g} / \mathrm{L}$, and the median platelet count was $49(8-804) \times 10^{9} / \mathrm{L}$.

\section{Treatment response}

All patients were eligible for response following the administration of D-CAG as induction therapy. A median number of 2 cycles of the D-CAG regimen (range from 1 to 7 cycles) were administrated. After the first cycle, ORR was $71.8 \%$ (84 patients); 68 (58.1\%) patients achieved CR, and $16(13.7 \%)$ patients had PR. After the second cycle, ORR and CR were $72.7 \%$ and $64.1 \%$, respectively.
Table 1 Baseline characteristics of the 117 patients with acute myeloid leukaemia

\begin{tabular}{|c|c|c|c|}
\hline \multirow[t]{2}{*}{ Characteristics } & \multicolumn{3}{|c|}{ Total $(N=117)$} \\
\hline & $\mathrm{N}$ & Median(range) & $\%$ \\
\hline Age & & $67(60-87)$ & \\
\hline \multicolumn{4}{|l|}{ Sex } \\
\hline Male & 64 & & 54.7 \\
\hline Female & 53 & & 45.3 \\
\hline \multicolumn{4}{|l|}{ ECOG } \\
\hline $0-2$ & 96 & & 82.1 \\
\hline$\geq 3$ & 21 & & 17.9 \\
\hline \multicolumn{4}{|l|}{ Diagnosis } \\
\hline MO & 3 & & 2.6 \\
\hline M1 & 19 & & 16.2 \\
\hline M2 & 57 & & 48.7 \\
\hline M4 & 8 & & 6.8 \\
\hline M5 & 18 & & 15.4 \\
\hline M6 & 10 & & 8.6 \\
\hline Unknown & 2 & & 1.7 \\
\hline \multicolumn{4}{|c|}{ Primary karyotype } \\
\hline Good & 1 & & 0.8 \\
\hline Intermediate & 89 & & 76.1 \\
\hline Poor & 18 & & 15.4 \\
\hline Unavailable & 9 & & 7.7 \\
\hline \multicolumn{4}{|c|}{ FLT3-ITD mutation } \\
\hline Positive & 13 & & 11.1 \\
\hline Negative & 88 & & 75.2 \\
\hline Missing & 16 & & 13.7 \\
\hline \multicolumn{4}{|l|}{ NPM1 mutation } \\
\hline Positive & 24 & & 20.5 \\
\hline Negative & 78 & & 66.7 \\
\hline Missing & 15 & & 12.8 \\
\hline \multicolumn{4}{|l|}{ CEBPa mutation } \\
\hline Positive & 16 & & 13.7 \\
\hline Negative & 81 & & 69.2 \\
\hline Missing & 20 & & 17.1 \\
\hline \multicolumn{4}{|l|}{ C-Kit mutation } \\
\hline Positive & 4 & & 3.5 \\
\hline Negative & 94 & & 80.3 \\
\hline Missing & 19 & & 16.2 \\
\hline \multicolumn{4}{|l|}{ Initial CBC } \\
\hline $\mathrm{WBC}\left(\times 10^{9} / \mathrm{L}\right)$ & & $6.92(0.3-310.3)$ & \\
\hline $\mathrm{Hb}(\times \mathrm{g} / \mathrm{L})$ & & $84(47-139)$ & \\
\hline $\operatorname{PLT}\left(\times 10^{9} / \mathrm{L}\right)$ & & 49(8-804) & \\
\hline
\end{tabular}

ECOG Eastern Cooperative Oncology Group, WBC white blood cells, $\mathrm{Hb}$ hemoglobin, PLT platelet 


\section{Prognostic factors for treatment response in elderly patients with AML}

We divided patients into three groups according to the treatment efficacy and analysed peripheral hemogram results, including leukocyte, haemoglobin and platelet counts, on day 7 , day 10 , and day 14 after the initial therapy. There was a statistically significant difference in terms of platelet count on day 14 in patients with CR compared with those who had PR and NR $(p<0.001)$ (Fig. 1). Median platelet counts in patients with $\mathrm{CR}, \mathrm{PR}$ and NR were $59.5 \times 10^{9} / \mathrm{L}$, $37 \times 10^{9} / \mathrm{L}$, and $28 \times 10^{9} / \mathrm{L}$, respectively. Therefore, we selected platelet counts threshold of $60 \times 10^{9} / \mathrm{L}$ (the integer value closest to the median value of the $\mathrm{CR}$ group) or $100 \times 10^{9} / \mathrm{L}$ (normal value) on day 14 after D-CAG and sorted all patients. There was no significant difference in the baseline characteristics between those who achieved and those who did not achieve platelet counts $\geq 60 \times 10^{9} / \mathrm{L}$ or $100 \times 10^{9} / \mathrm{L}$ (Table 2 ). The $\mathrm{CR}$ in patients with platelet counts $\geq 60 \times 10^{9} / \mathrm{L}$ and $<60 \times 10^{9} / \mathrm{L}$ were 80.9 and $45.3 \%$, respectively $(p<0.001)$. Patients with platelet counts $\geq 100 \times$ $10^{9} / \mathrm{L}$ achieved a higher CR rate compared with those who did not $(85.2 \%$ vs. $50 \% p=0.001)$ (Table 3, Fig. 2 ).

For patients with intermediate cytogenetics at the time of diagnosis, CR was achieved by 53 patients (59.6\%). Ten patients (11.2\%) had PR, and twenty-six patients (29.2\%) did not respond. For poor cytogenetics, CR was 61.1\% (11/18), and PR was $16.7 \%(3 / 18)$. There were no significant differences in the CR and ORR rates between the two different cytogenetic risk groups $\left(\mathrm{X}^{2}=0.015\right.$ $\left.p=0.902 ; \mathrm{X}^{2}=0.363 p=0.547\right)$.

For patients harbouring FLT3-ITD mutations or wild-type FLT3-ITD, the CR rates were 46.2 and $62.5 \%$, respectively $(p=0.261)$. Patients with wild-type FLT3-ITD achieved higher ORR compared with those with FLT3-ITD mutations (77.3\% vs. $46.2 \% p=0.042$ ). Patients with or without NPM1 mutations had a CR rate of $62.5 \%$ and $58.9 \%(p=0.758)$, respectively. The ORR was $70.8 \%$ and $73.1 \%(p=0.829)$.

Multivariate analysis indicated that the platelet counts $\geq 100 \times 10^{9} / \mathrm{L}$ on day 14 after treatment was associated with CR (Table 4).

\section{Survival}

Among all patients, one patient underwent bone marrow puncture to evaluate treatment efficacy on day 14 after chemotherapy due to fast recovery of peripheral hemogram. Meanwhile, that day was the last follow-up of this study. Upon final analysis, a total of 77 deaths occurred in this study. The median OS of the cohort group was 13.9 months (range:0-55.1 months) and DFS of the patients achieving $\mathrm{CR}$ after the initial chemotherapy was 13.8 months.

\section{Prognostic factors for OS and DFS}

We dichotomized patients into those achieving a platelet count $\geq 60 \times 10^{9} / \mathrm{L}$ or $100 \times 10^{9} / \mathrm{L}$ vs. those who did not. The early recovery of platelets was not associated with

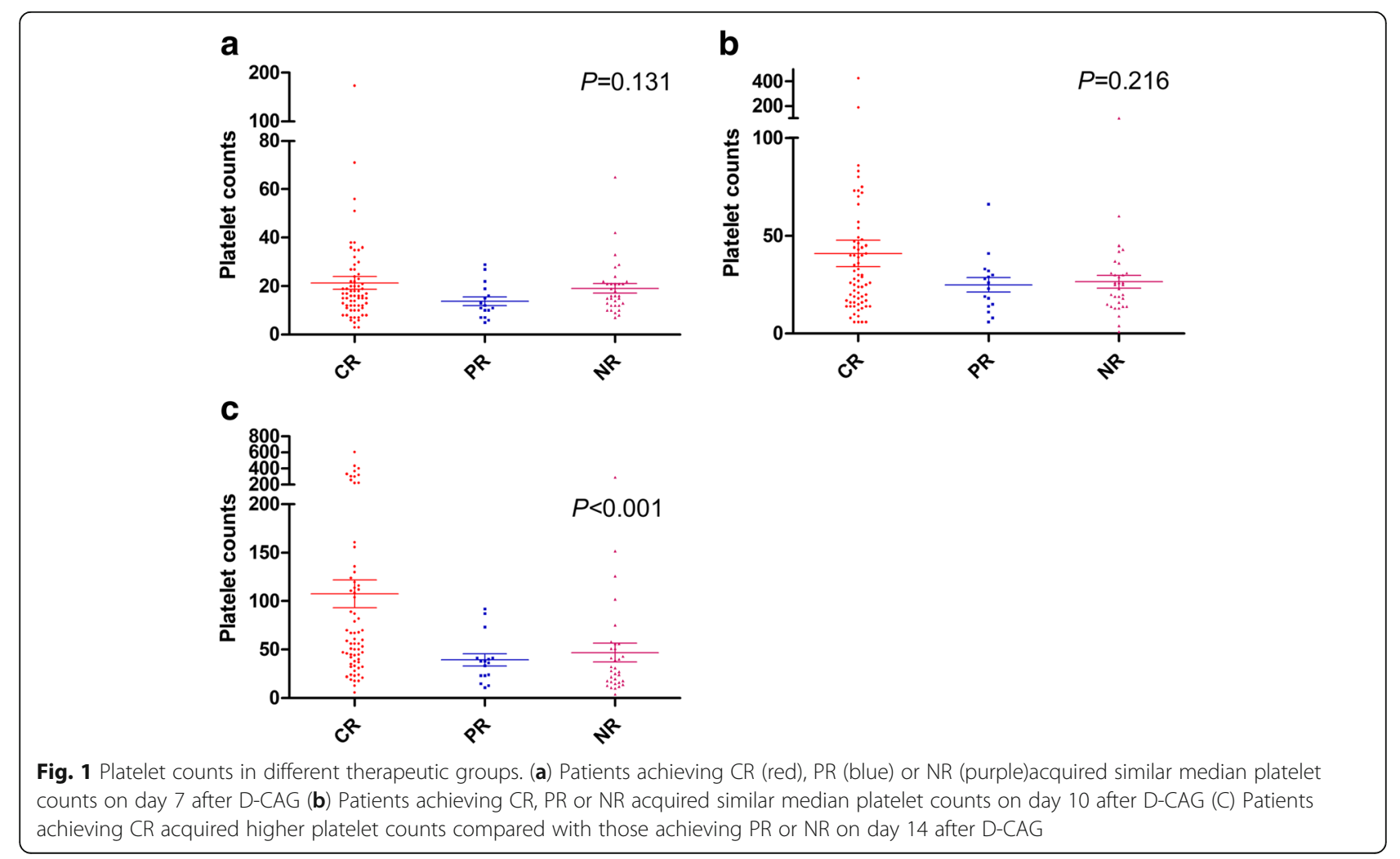


Table 2 Patients' clinical characteristics post-treatment, by recovery of platelet counts

\begin{tabular}{|c|c|c|c|c|c|c|c|c|c|c|}
\hline \multirow[t]{2}{*}{ Characteristics } & \multicolumn{2}{|c|}{$\begin{array}{l}\mathrm{PLT} \geq 60 \times 10^{9} / \mathrm{L} \\
(N=42)\end{array}$} & \multicolumn{2}{|c|}{$\begin{array}{l}\mathrm{PLT}<60 \times 10^{9} / \mathrm{L} \\
(N=75)\end{array}$} & \multirow[t]{2}{*}{$P$} & \multicolumn{2}{|c|}{$\begin{array}{l}\mathrm{PLT} \geq 100 \times 10^{9} / \mathrm{L} \\
(N=27)\end{array}$} & \multicolumn{2}{|c|}{$\begin{array}{l}\mathrm{PLT}<100 \times 10^{9} / \mathrm{L} \\
(N=90)\end{array}$} & \multirow[t]{2}{*}{$P$} \\
\hline & $\mathrm{N}$ & Median (range) & $\mathrm{N}$ & Median (range) & & $\mathrm{N}$ & Median (range) & $\mathrm{N}$ & Median (range) & \\
\hline Age(years) & & $68.5(60-87)$ & & $66(60-84)$ & 0.458 & & $69(60-87)$ & & $66(60-84)$ & 0.619 \\
\hline Sex & & & & & 0.706 & & & & & 0.435 \\
\hline Male & 22 & & 42 & & & 13 & & 51 & & \\
\hline Female & 20 & & 33 & & & 14 & & 39 & & \\
\hline ECOG & & & & & 0.076 & & & & & 0.18 \\
\hline $0-2$ & 38 & & 58 & & & 25 & & 71 & & \\
\hline$\geq 3$ & 4 & & 17 & & & 2 & & 19 & & \\
\hline Diagnosis & & & & & 0.305 & & & & & 0.771 \\
\hline MO & 0 & & 3 & & & 0 & & 3 & & \\
\hline M1 & 9 & & 10 & & & 3 & & 16 & & \\
\hline M2 & 22 & & 35 & & & 14 & & 43 & & \\
\hline M4 & 2 & & 6 & & & 2 & & 6 & & \\
\hline M5 & 5 & & 13 & & & 5 & & 13 & & \\
\hline M6 & 2 & & 8 & & & 2 & & 8 & & \\
\hline Unknown & 2 & & 0 & & & 1 & & 1 & & \\
\hline Primary karyotype & & & & & 0.202 & & & & & 0.525 \\
\hline Good & 0 & & 1 & & & 0 & & 1 & & \\
\hline Intermediate & 36 & & 53 & & & 23 & & 66 & & \\
\hline Poor & 4 & & 14 & & & 3 & & 15 & & \\
\hline Unavailable & 2 & & 7 & & & 1 & & 8 & & \\
\hline FLT3-ITD mutation & & & & & 0.81 & & & & & 0.681 \\
\hline Positive & 4 & & 9 & & & 2 & & 11 & & \\
\hline Negative & 34 & & 54 & & & 22 & & 66 & & \\
\hline Missing & 4 & & 12 & & & 3 & & 13 & & \\
\hline NPM1 mutation & & & & & 0.609 & & & & & 0.722 \\
\hline Positive & 10 & & 14 & & & 5 & & 19 & & \\
\hline Negative & 28 & & 50 & & & 19 & & 59 & & \\
\hline Missing & 4 & & 11 & & & 3 & & 12 & & \\
\hline CEBPa mutation & & & & & 0.126 & & & & & 0.107 \\
\hline Positive & 9 & & 7 & & & 7 & & 9 & & \\
\hline Negative & 29 & & 52 & & & 17 & & 64 & & \\
\hline Missing & 4 & & 16 & & & 3 & & 17 & & \\
\hline C-Kit mutation & & & & & 1.000 & & & & & 1.000 \\
\hline Positive & 2 & & 2 & & & 1 & & 3 & & \\
\hline Negative & 36 & & 58 & & & 23 & & 71 & & \\
\hline Missing & 4 & & 15 & & & 3 & & 16 & & \\
\hline \multicolumn{11}{|l|}{ Initial CBC } \\
\hline $\begin{array}{l}\text { WBC } \\
\left(\times 10^{9} / L\right)\end{array}$ & & $\begin{array}{l}11.575 \\
(0.3-310.3)\end{array}$ & & $\begin{array}{l}6.23 \\
(0.7-239.24)\end{array}$ & 0.475 & & $\begin{array}{l}4.02 \\
(0.3-196.8)\end{array}$ & & $\begin{array}{l}9.29 \\
(0.7-310.3)\end{array}$ & 0.452 \\
\hline $\begin{array}{l}\mathrm{Hb} \\
(\times g / L)\end{array}$ & & $\begin{array}{l}89.5 \\
(56-128)\end{array}$ & & $\begin{array}{l}81 \\
(47-139)\end{array}$ & 0.097 & & $\begin{array}{l}89 \\
(57-113)\end{array}$ & & $\begin{array}{l}82 \\
(47-139)\end{array}$ & 0.785 \\
\hline $\begin{array}{l}\text { PLT } \\
\left(\times 10^{9} / \mathrm{L}\right)\end{array}$ & & $\begin{array}{l}56.5 \\
(8-804)\end{array}$ & & $\begin{array}{l}43 \\
(9-575)\end{array}$ & 0.106 & & $\begin{array}{l}72 \\
(8-804)\end{array}$ & & $\begin{array}{l}44 \\
(9-789)\end{array}$ & 0.167 \\
\hline
\end{tabular}


Table 3 Platelet counts on day 14 reflect response and survival

\begin{tabular}{|c|c|c|c|c|c|c|}
\hline & $\begin{array}{l}\mathrm{PLT} \geq 60 \times 10^{9} / \mathrm{L} \\
(N=42)\end{array}$ & $\begin{array}{l}\mathrm{PLT}<60 \times 10^{9} / \mathrm{L} \\
(N=75)\end{array}$ & $P$ & $\begin{array}{l}\mathrm{PLT} \geq 100 \times 10^{9} / \mathrm{L} \\
(N=27)\end{array}$ & $\begin{array}{l}\mathrm{PLT}<100 \times 10^{9} / \mathrm{L} \\
(N=90)\end{array}$ & $P$ \\
\hline ORR (\%) & 88.1 & 62.7 & 0.003 & 85.2 & 67.8 & 0.078 \\
\hline CR (\%) & 80.9 & 45.3 & $<0.001$ & 85.2 & 50 & 0.001 \\
\hline NR (\%) & 11.9 & 37.3 & & 14.8 & 32.2 & \\
\hline OS (months) & 16.5 & 9.1 & 0.009 & 31 & 10.1 & 0.003 \\
\hline \multicolumn{7}{|l|}{ First CR } \\
\hline DFS (months) & 16.3 & 7.4 & 0.024 & 16.9 & 8.9 & 0.006 \\
\hline
\end{tabular}

PLT platelet, CR complete remission, ORR overall response rate, NR no remission, OS overall survival, DFS disease-free survival

the patient age, sex, karyotype or pre-treatment peripheral blood cell counts (Table 2). OS was significantly longer among patients achieving a platelet count $\geq 60 \times 10^{9} / \mathrm{L}$ or $100 \times 10^{9} / \mathrm{L}$ compared to patients who did not, after initiation of the first cycle of induction therapy (median OS: 16.5 vs. 9.1 months $p=$ 0.009 and 31 vs. 10.1 months $p=0.003$ Table 3 Fig. $3 \mathrm{a}$, b). As showed in Table 5, patients with ECOG 0-2 had significantly longer OS compared to those with ECOG $\geq 3$ (median value: 15.7 vs. 6 months $p=0.005$ Fig. 3c). Survival was shorter for patients with poor karyotype in comparison with patients with intermediate karyotype (median OS: 8.2 vs. 15.9 months $p=$ 0.006 Fig. 3d). Median OS was 14.8 months for patients without FLT-ITD3 mutation and 4 months for patients with mutation (Fig. 3e). CR Patients after first cycle of induction treatment with receiving with platelet counts $\geq 60 \times 10^{9} / \mathrm{L}$ or $100 \times 10^{9} / \mathrm{L}$ also acquired longer DFS (median value:16.3 vs. 7.4 months $p=0.024$ and 16.9 vs. 8.9 months $p=0.006$ Fig. 4). In an exploratory analysis using a multivariate Cox proportional hazards model, poor cytogenetics $(p=0.010)$ and FLT3-ITD mutation $(p=0.007)$ were identified as the independent adverse prognostic factors, but not platelet count on day $14(p=0.091)$. Platelet count on day 14 was of independent prognostic importance for DFS $(p=0.035)$.

\section{Discussion}

This study targeted elderly AML patients who received decitabine-based chemotherapy. Reliable clinical or molecular parameters that can be used as prognostic marker of benefit from decitabine-based chemotherapy in patients with AML are not defined. An interesting finding from this study was that differences at the platelet level on day 14 after D-CAG correlate with response to decitabine-based chemotherapy and survival benefit in elderly AML patients. Based on a data analysis from 6283 AML patients receiving cytarabinebased therapy, Walter and colleagues [19] found that the patients with CR had superior relapse-free survival (RFS) compared with those achieving CRi (CR with incomplete platelet recovery), suggesting that platelet recovery may be potentially associated with survival. The consensus finding is that a quicker time to platelet recovery or platelet counts $\geq 500 \times 10^{9} / \mathrm{L}$ at 28 days after one course of induction chemotherapy initiation correlated with RFS and OS in patients with acute leukaemia who entered CR [20,21].

Nevertheless, it remains controversial which time points after induction are of most prognostic significance or what quantifiable levels of minimal residual disease are most reliable in defining the prognosis of patients [20]. According to the previous study, the platelet count after induction therapy may serve as an index reflecting the amount of
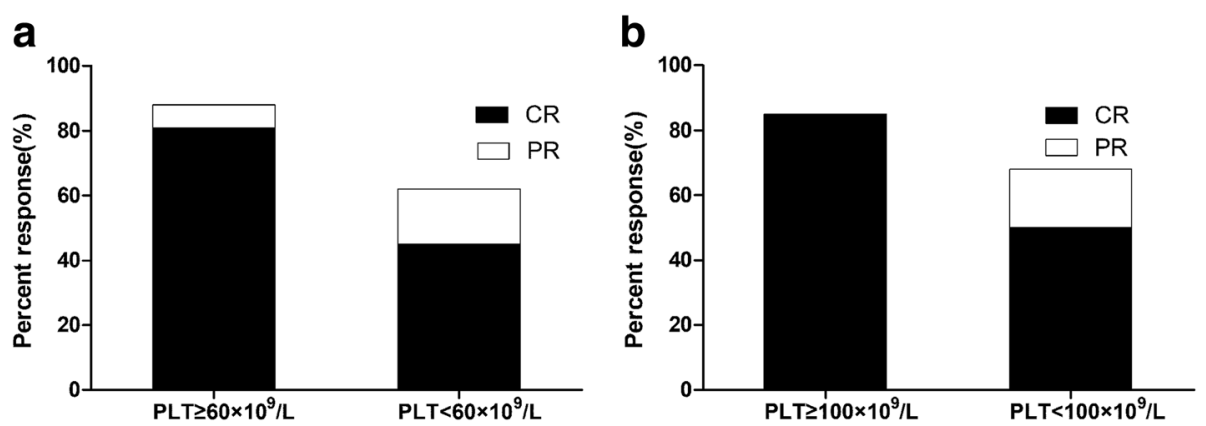

Fig. 2 Response rates for selected subgroups. CR was noted in black, and additional patients with partial remission were noted in white. (a) Patients with platelet count $\geq 60 \times 10^{9} / \mathrm{L}$ acquired significant higher CR and ORR compared with those with platelet count $<60 \times 10^{9} / \mathrm{L} ;(\mathbf{b})$ Patients with platelet count $\geq 100 \times 10^{9} / \mathrm{L}$ acquired significant higher CR but not ORR compared with those with platelet count $<100 \times 10^{9} / \mathrm{L}$ 
Table 4 Multivariate analysis for CR and ORR

\begin{tabular}{|c|c|c|c|c|c|c|}
\hline \multirow[t]{2}{*}{ Characteristics } & \multicolumn{3}{|l|}{$C R$} & \multicolumn{3}{|l|}{ ORR } \\
\hline & $\overline{\operatorname{EXP}(B)}$ & $P$ & $95 \% \mathrm{Cl}$ & $\overline{\operatorname{EXP}(B)}$ & $P$ & $95 \% \mathrm{Cl}$ \\
\hline FLT3-ITD mutation & & 0.716 & & & 0.140 & \\
\hline CEBPa mutation & & 0.159 & & & 0.998 & \\
\hline Day-14 PLT & 4.231 & 0.016 & $1.314-13.622$ & & 0.512 & \\
\hline
\end{tabular}

$C R$ complete remission, $O R R$ overall response rate, $\operatorname{EXP}(B)$ the exponent of $\mathrm{B}, \mathrm{Cl}$ confidence interval, PLT platelet

minimal residual for AML patients with $\mathrm{CR}$, as well as the degree of recovery upon exposure of normal progenitors to chemotherapy injure [20,22]. Our observation of close relationships among platelet count, $\mathrm{CR}$ and survival seem to be based on a similar phenomenon.

Unlike unaccompanied HMA treatments, which require several courses (four to six cycles) to achieve a response and are often needed to discern the effect of the therapy, responses could be observed after one cycle of conventional chemotherapy, including decitabine-based chemotherapy [4, 20, 21, 23]. It has been reported that low-dose decitabine promotes normal megakaryocyte outgrowth and differentiation of normal megakaryocytes into platelets [12, 13]. To our knowledge, the impact of early platelet regeneration to prognosis after decitabine-based chemotherapy has not been studied in a systematic fashion in AML before.

We evaluated the effect of baseline biomarkers, molecular mutation or clinical variables, especially the regeneration of haematopoiesis, on day 7, day 10 and day 14 after D-CAG. Consistent with the results from our previous study [4], there was no statistical significance of CR rate between patients with poor and intermediate karyotype. Also, patients with or without FLT3-ITD mutation acquired similar $\mathrm{CR}$ rate. Those results indicated that patients at
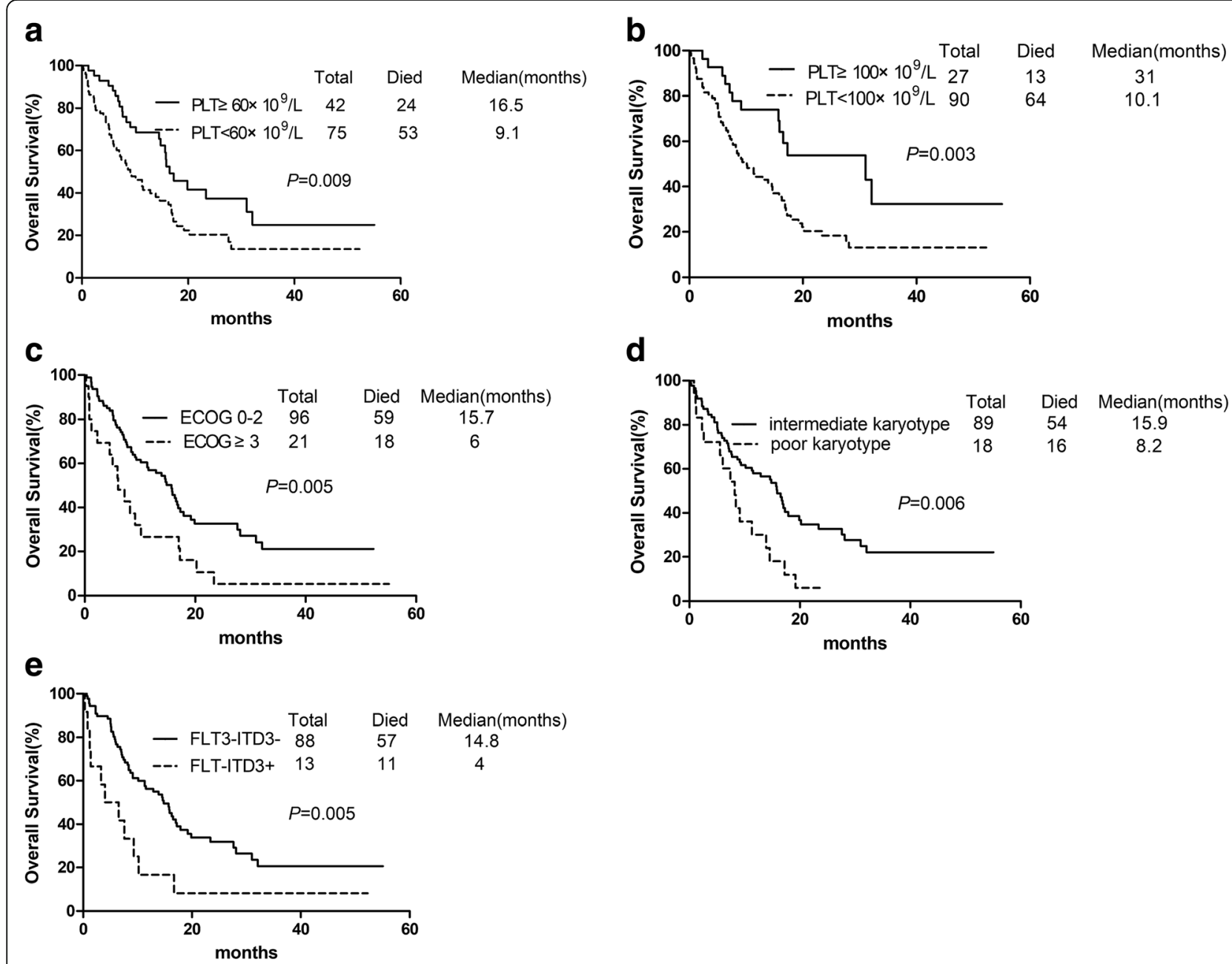

Fig. 3 Overall Survival. (a) Patients with platelet count $\geq 60 \times 10^{9} / \mathrm{L}$ (solid line) had longer OS than PLT $<60 \times 10^{9} / \mathrm{L}$ (imaginary line) (b) Patients with platelet count $\geq 100 \times 10^{9} / \mathrm{L}$ (solid line) had longer OS than PLT $<100 \times 10^{9} / \mathrm{L}$ (imaginary line) (c) Patients with good performance status (solid line) had longer OS than poor status (imaginary line) (d) Patients with intermediate karyotype (solid line) had longer OS than poor karyotype (imaginary line) (e) Patients without FLT-ITD3 mutation (solid line) had longer OS than with mutation (imaginary line) 
Table 5 Prognostic factors of overall survival and disease-free survival

\begin{tabular}{|c|c|c|c|c|c|c|c|c|c|c|}
\hline \multirow[t]{3}{*}{ Characteristics } & \multicolumn{5}{|l|}{ OS } & \multicolumn{5}{|l|}{ DFS } \\
\hline & \multicolumn{2}{|c|}{ Univariate analysis } & \multicolumn{3}{|c|}{ Multivariate analysis } & \multicolumn{2}{|c|}{ Univariate analysis } & \multicolumn{3}{|c|}{ Multivariate analysis } \\
\hline & Median & $P$ & $\overline{H R}$ & $P$ & $95 \% \mathrm{Cl}$ & Median & $P$ & $\overline{H R}$ & $P$ & $95 \% \mathrm{Cl}$ \\
\hline Age & & 0.131 & & & & & 0.573 & & & \\
\hline $60-70$ & 15.8 & & & & & 14 & & & & \\
\hline$\geq 70$ & 8.2 & & & & & 10 & & & & \\
\hline Sex & & 0.858 & & & & & 0.906 & & & \\
\hline Male & 12.9 & & & & & 13.8 & & & & \\
\hline Female & 14.6 & & & & & 13 & & & & \\
\hline ECOG & & 0.005 & 1.748 & 0.075 & $0.945-3.233$ & & 0.109 & & & \\
\hline $0-2$ & 15.7 & & & & & 13.8 & & & & \\
\hline$\geq 3$ & 6 & & & & & 5 & & & & \\
\hline FAB classification & & 0.67 & & & & & 0.451 & & & \\
\hline MO & 4.5 & & & & & / & & & & \\
\hline M1 & 10.2 & & & & & 10 & & & & \\
\hline M2 & 13.9 & & & & & 13 & & & & \\
\hline M4 & 8.7 & & & & & 14.1 & & & & \\
\hline M5 & 11.3 & & & & & 14.2 & & & & \\
\hline M6 & 15.7 & & & & & 6.3 & & & & \\
\hline Primary karyotype & & 0.006 & 2.272 & 0.010 & $1.213-4.258$ & & 0.045 & 1.768 & 0.127 & $0.850-3.680$ \\
\hline Intermediate & 15.9 & & & & & 15.2 & & & & \\
\hline Poor & 8.2 & & & & & 7 & & & & \\
\hline FLT3-ITD mutation & & 0.005 & 2.669 & 0.007 & $1.304-5.461$ & & 0.352 & & & \\
\hline Positive & 4 & & & & & 7.6 & & & & \\
\hline Negative & 14.8 & & & & & 13.8 & & & & \\
\hline NPM1 mutation & & 0.987 & & & & & 0.782 & & & \\
\hline Positive & 16.5 & & & & & 14.2 & & & & \\
\hline Negative & 13.9 & & & & & 10 & & & & \\
\hline CEBPa mutation & & 0.132 & & & & & 0.089 & & & \\
\hline Positive & 23.4 & & & & & 17.4 & & & & \\
\hline Negative & 13.9 & & & & & 10 & & & & \\
\hline C-Kit mutation & & 0.067 & & & & & 0.987 & & & \\
\hline Positive & 5 & & & & & 16 & & & & \\
\hline Negative & 14.6 & & & & & 11.9 & & & & \\
\hline Day-14 platelet count & & 0.003 & 0.571 & 0.091 & $0.298-1.094$ & & 0.006 & 0.468 & 0.035 & $0.231-0.947$ \\
\hline $\mathrm{PLT} \geq 100 \times 10^{9} / \mathrm{L}$ & 31 & & & & & 16.9 & & & & \\
\hline $\mathrm{PLT}<100 \times 10^{9} / \mathrm{L}$ & 10.1 & & & & & 8.9 & & & & \\
\hline
\end{tabular}

OS overall survival, DFS disease-free survival, HR hazard ratio, Cl confidence interval, ECOG Eastern Cooperative Oncology Group, PLT platelet

high risks could also benefit from decitabine induction therapy. The association between molecular or clinical biomarkers and decitabine response may be confounded by the variations in enzymes responsible for the activation and metabolism of decitabine [9]. Thus, it is clear that the evaluation of data collected after treatment may be more useful compared with evaluation of pre-treatment data, including cytogenetics and various genetic abnormalities [22].
With the aim of identifying patients who will derive the greatest clinical benefit from decitabine-based chemotherapy, we analysed post-treatment findings to assess CR and OS that have focused on laboratory parameters, measured during the course of induction or at the time of CR. Here, we analysed whether platelet count, a much simpler test, on days 7,10 , and 14 after induction therapy might also be associated with CR and OS. We found superior CR and 

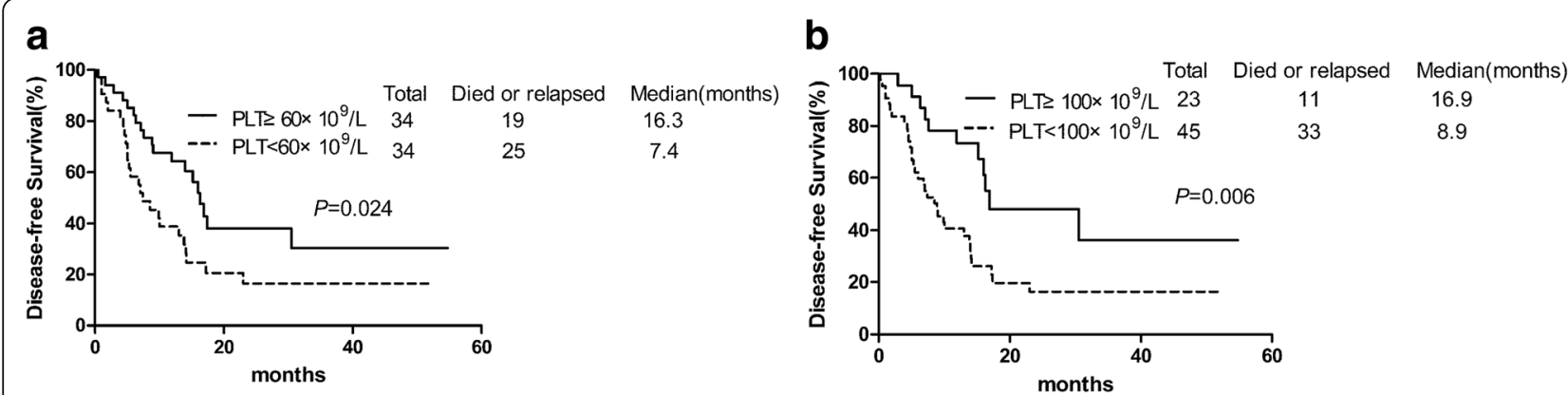

Fig. 4 Disease-free Survival. (a) Patients with platelet count $\geq 60 \times 10^{9} / \mathrm{L}$ (solid line) had longer DFS than PLT $<60 \times 10^{9} / \mathrm{L}$ (imaginary line) (b) Patients with platelet count $\geq 100 \times 10^{9} / \mathrm{L}$ (solid line) had longer DFS than PLT $<100 \times 10^{9} / \mathrm{L}$ (imaginary line)

survival in elderly AML patients with early recovery of platelet counts after one course of D-CAG and demonstrated that early hyper-recovery of platelet counts is a prognostic factor independent of other known prognostic factors in elderly AML patients who received D-CAG. Our results revealed that patients achieving CR, PR or CR had similar peripheral hemogram results on day 7 and day 10 after D-CAG. On day 14, patients achieving CR attained higher platelet counts compared with those achieving PR or NR $\left(59.5 \times 10^{9} / \mathrm{L}, 37 \times 10^{9} / \mathrm{L}\right.$ and $28 \times$ $\left.10^{9} / \mathrm{L} p<0.001\right)$. CR was shown to be an important prognostic marker of longer survival [24]. Furthermore, we dichotomized patients into those who achieved a platelet count $\geq 60 \times 10^{9} / \mathrm{L}$ (the integer value closest to the median count of the CR group) or $\geq 100 \times 10^{9} / \mathrm{L}$ (normal value) on day 14 after D-CAG versus those who did not. Using this category, we also found that differences at the platelet level correlated with response to decitabine-based chemotherapy and superior survival in elderly AML patients.

\section{Conclusions}

Poor ECOG, unfavourable cytogenetics and FLT3-ITD mutation are, prior to treatment, poor prognostic indicators for elderly patients with AML. Based on the results of this study, a platelet count $\geq 60 \times 10^{9} / \mathrm{L}$ or $\geq 100 \times 10^{9} / \mathrm{L}$ on day 14 after decitabine combined chemotherapy was associated with increase response rate in the clinic. Also, the association of platelet count with longer OS and DFS was revealed through univariate analyses. With better definitions of subsets of patients, there is likely to be a role for aiding the physician decision-making process in our various prognostic models. However, since this study is an analysis of a limited sample size, independent validation of large-scale patients is needed in the future.

\section{Additional file}

Additional file 1: Figure S1. Enrollment and outcomes. $127 \mathrm{AML}$ patients were administrated with decitabine for 5 consecutive days (day $1-5$ ) and G-CSF (day 0-9) in combination with cytarabine (day 3-9), aclarubicin for 4 days (day 3-6) (D-CAG). Only 117 patients were available to obtain blood routine and efficacy data after the first course of treatment. The results showed 68 patients acquired CR, 16 patients PR and 33 patients NR. The platelet counts on day 14 after D-CAG of three groups were $59.5 \times 10^{9} / \mathrm{L}, 37 \times 10^{9} / \mathrm{L}$ and $28 \times 10^{9} / \mathrm{L}$. Partial patients who acquired PR or NR received second cycle of D-CAG induction therapy. (DOC $52 \mathrm{~kb})$

\section{Abbreviations}

AML: Acute myeloid leukaemia; Cl: Confidence interval; CR: Complete remission; DFS: Disease-free survival; Hb: Haemoglobin; HR: Hazard ratios; ORR: Overall response rate; OS: Overall survival; PR: Partial remission; RFS: Relapse-free survival; WBC: White blood cells

\section{Acknowledgements}

Not applicable.

\section{Funding}

This work was supported by the National Natural Science Foundation of the People's Republic of China [No. 81570134], National Public Health Grand Research Foundation [No. 201202017], A Project Funded by the Priority Academic Program Development of Jiangsu Higher Education Institute [No. JX10231801] and Key Project of Jiangsu Province Health Agency [No. K201107]. The funding body have no impact on design of the study and data acquisition, analysis, and interpretation of data and compilation of the manuscript.

\section{Availability of data and materials}

All data generated or analyzed during this study are included in this published article and raw data are available from the corresponding author upon request.

\section{Authors' contributions}

SQ and $J L$ conceived and designed the study. JH, HZ, YL and SL performed acquisition of data. $\mathrm{JH}, \mathrm{HZ}, \mathrm{MH}, \mathrm{HZ}$ and $\mathrm{YZ}$ were involved in analyzing or interpreting research data. $J \mathrm{H}$ draft the manuscript and $\mathrm{MH}, \mathrm{YZ}, \mathrm{JL}, \mathrm{SQ}$ revised the manuscript strictly for important content. All authors have read and approved the final manuscript.

\section{Ethics approval and consent to participate}

Our study was approved by the ethic committee of the First Affiliated Hospital of Nanjing Medical University, Jiangsu Province Hospital on September 15, 2011 and registered at http://www.chictr.org.cn/ as ChiCTRONC-11,001,700 on 28 September 2011. The treatment regimen was performed in accordance with the Declaration of Helsinki. Written informed consent was obtained from all patients or legal trustee.

\section{Consent for publication}

Not applicable.

\section{Competing interests}

The authors declare that they have no competing interests. 


\section{Publisher's Note}

Springer Nature remains neutral with regard to jurisdictional claims in published maps and institutional affiliations.

\section{Author details}

'Department of Hematology, The First Affiliated Hospital of Nanjing Medical University, Jiangsu Province Hospital, 300 Guangzhou Road, Nanjing 210029, China. ${ }^{2}$ Department of Oncology, The Second Affiliated Hospital of Southeast University, Zhongfu Road 1-1, Nanjing 210003, China.

Received: 9 April 2018 Accepted: 29 November 2018 Published online: 19 December 2018

\section{References}

1. Stone RM. The difficult problem of acute myeloid leukemia in the older adult. CA Cancer J Clin. 2002;52(6):363-71.

2. Daver N, Kantarjian H, Ravandi F, Estey E, Wang X, Garcia-Manero G, Jabbour E, Konopleva M, O'Brien S, Verstovsek S, et al. A phase II study of decitabine and gemtuzumab ozogamicin in newly diagnosed and relapsed acute myeloid leukemia and high-risk myelodysplastic syndrome. Leukemia. 2016; 30(2):268-73.

3. Kantarjian HM, Thomas XG, Dmoszynska A, Wierzbowska A, Mazur G, Mayer J, Gau JP, Chou WC, Buckstein R, Cermak J, et al. Multicenter, randomized, open-label, phase III trial of decitabine versus patient choice, with physician advice, of either supportive care or low-dose cytarabine for the treatment of older patients with newly diagnosed acute myeloid leukemia. J Clin Oncol. 2012;30(21):2670-7.

4. Li J, Chen Y, Zhu Y, Zhou J, Xu Y, Li Y, Yu K, Pan L, Wang J, Ding J, et al. Efficacy and safety of decitabine in combination with G-CSF, low-dose cytarabine and aclarubicin in newly diagnosed elderly patients with acute myeloid leukemia. Oncotarget. 2015;6(8):6448-58.

5. Welch JS, Klco JM, Gao F, Procknow E, Uy GL, Stockerl-Goldstein KE, Abboud CN, Westervelt P, DiPersio JF, Hassan A, et al. Combination decitabine, arsenic trioxide, and ascorbic acid for the treatment of myelodysplastic syndrome and acute myeloid leukemia: a phase I study. Am J Hematol. 2011;86(9):796-800.

6. Voso MT, Santini V, Fabiani E, Fianchi L, Criscuolo M, Falconi G, Guidi F, Hohaus $\mathrm{S}$, Leone $\mathrm{G}$. Why methylation is not a marker predictive of response to hypomethylating agents. Haematologica. 2014;99(4):613-9.

7. Braun T, Itzykson R, Renneville A, de Renzis B, Dreyfus F, Laribi K Bouabdallah K, Vey N, Toma A, Recher C, et al. Molecular predictors of response to decitabine in advanced chronic myelomonocytic leukemia: a phase 2 trial. Blood. 2011;118(14):3824-31.

8. Klco JM, Spencer DH, Lamprecht TL, Sarkaria SM, Wylie T, Magrini V, Hundal J, Walker J, Varghese N, Erdmann-Gilmore P, et al. Genomic impact of transient low-dose decitabine treatment on primary AML cells. Blood. 2013; 121(9):1633-43.

9. Bejar R, Lord A, Stevenson K, Bar-Natan M, Perez-Ladaga A, Zaneveld J, Wang H, Caughey B, Stojanov P, Getz G, et al. TET2 mutations predict response to hypomethylating agents in myelodysplastic syndrome patients. Blood. 2014;124(17):2705-12

10. Marcucci G, Haferlach T, Dohner H. Molecular genetics of adult acute myeloid leukemia: prognostic and therapeutic implications. J Clin Oncol. 2011;29(5):475-86.

11. Lee EJ, Zeidan AM. Genome sequencing in myelodysplastic syndromes: can molecular mutations predict benefit from hypomethylating agent therapy? Expert Rev Hematol. 2015;8(2):155-8.

12. Zhou H, Hou Y, Liu X, Qiu J, Feng Q, Wang Y, Zhang X, Min Y, Shao L, Liu X, et al. Low-dose decitabine promotes megakaryocyte maturation and platelet production in healthy controls and immune thrombocytopenia. Thromb Haemost. 2015;113(5):1021-34.

13. Wang J, Yi Z, Wang S, Li Z. The effect of decitabine on megakaryocyte maturation and platelet release. Thromb Haemost. 2011:106(2):337-43.

14. Jung HA, Maeng $\mathrm{CH}$, Kim M, Kim S, Jung CW, Jang JH. Platelet response during the second cycle of decitabine treatment predicts response and survival for myelodysplastic syndrome patients. Oncotarget. 2015;6(18):16653-62.

15. Alatrash G, Pelosini M, Saliba RM, Koca E, Rondon G, Andersson BS, Chiattone A, Zhang W, Giralt SA, Cernosek AM, et al. Platelet recovery before allogeneic stem cell transplantation predicts posttransplantation outcomes in patients with acute myelogenous leukemia and myelodysplastic syndrome. Biol Blood Marrow Transplant. 2011;17(12):1841-5.
16. Zeidan AM, Lee JW, Prebet T, Greenberg P, Sun Z, Juckett M, Smith MR, Paietta E, Gabrilove J, Erba HP, et al. Platelet count doubling after the first cycle of azacitidine therapy predicts eventual response and survival in patients with myelodysplastic syndromes and oligoblastic acute myeloid leukaemia but does not add to prognostic utility of the revised IPSS. Br J Haematol. 2014;167(1):62-8.

17. Cheson BD, Bennett JM, Kopecky KJ, Buchner T, Willman CL, Estey EH, Schiffer CA, Doehner H, Tallman MS, Lister TA, et al. Revised recommendations of the international working Group for Diagnosis, standardization of response criteria, treatment outcomes, and reporting standards for therapeutic trials in acute myeloid leukemia. J Clin Oncol. 2003;21(24):4642-9.

18. Dohner H, Estey EH, Amadori S, Appelbaum FR, Buchner T, Burnett AK, Dombret H, Fenaux P, Grimwade D, Larson RA, et al. Diagnosis and management of acute myeloid leukemia in adults: recommendations from an international expert panel, on behalf of the European LeukemiaNet. Blood. 2010;115(3):453-74.

19. Walter RB, Kantarjian HM, Huang X, Pierce SA, Sun Z, Gundacker HM, Ravandi F, Faderl SH, Tallman MS, Appelbaum FR, et al. Effect of complete remission and responses less than complete remission on survival in acute myeloid leukemia: a combined eastern cooperative oncology group, southwest oncology group, and M. D. Anderson Cancer center study. J Clin Oncol. 2010;28(10):1766-71.

20. Chen X, Xie H, Wood BL, Walter RB, Pagel JM, Becker PS, Sandhu VK, Abkowitz JL, Appelbaum FR, Estey EH. Relation of clinical response and minimal residual disease and their prognostic impact on outcome in acute myeloid leukemia. J Clin Oncol. 2015;33(11):1258-64.

21. Yamazaki E, Kanamori H, Itabashi M, Ogusa E, Numata A, Yamamoto W, Ito S, Tachibana T, Hagihara M, Matsumoto K, et al. Hyper-recovery of platelets after induction therapy is a predictor of relapse-free survival in acute myeloid leukemia. Leuk Lymphoma. 2017;58(1):104-9.

22. Yanada M, Borthakur G, Garcia-Manero G, Ravandi F, Faderl S, Pierce S, Kantarjian H, Estey E. Blood counts at time of complete remission provide additional independent prognostic information in acute myeloid leukemia. Leuk Res. 2008:32(10):1505-9.

23. Behl D, Porrata LF, Markovic SN, Letendre L, Pruthi RK, Hook CC, Tefferi A, Elliot MA, Kaufmann SH, Mesa RA, et al. Absolute lymphocyte count recovery after induction chemotherapy predicts superior survival in acute myelogenous leukemia. Leukemia. 2006:20(1):29-34.

24. Yang AS, Doshi KD, Choi SW, Mason JB, Mannari RK, Gharybian V, Luna R, Rashid A, Shen L, Estecio MR, et al. DNA methylation changes after 5-aza-2'deoxycytidine therapy in patients with leukemia. Cancer Res. 2006;66(10): 5495-503.

Ready to submit your research? Choose BMC and benefit from:

- fast, convenient online submission

- thorough peer review by experienced researchers in your field

- rapid publication on acceptance

- support for research data, including large and complex data types

- gold Open Access which fosters wider collaboration and increased citations

- maximum visibility for your research: over $100 \mathrm{M}$ website views per year

At $\mathrm{BMC}$, research is always in progress.

Learn more biomedcentral.com/submissions 